
$\$ 3.50$

\title{
AN OXIDE DISPERSION STRENGTHENED Ni-W-AI ALLOY WITH SUPERIOR HIGH TEMPERATURE STRENGTH
}

by Thomas K. Glasgow

Lewis Research Center

Cleveland, Ohio 44135

TECHNICAL PAPER to be presented at

Third International Symposium sponsored

by the American Institute of Mining,

Metallurgical and Petroleum Engineers

Seven Springs, Pennsylvania, September 12-15, 1976 
. 

AN OXIDE DISPERSION STRENGTHENED Ni-W-AI ALLOY

WITH SUPERIOR HIGH TEMPERATURE STRENGTH

by Thomas K. Glasgow

NASA-Lewis Research Center

Cleveland, Ohio 44135

$\sigma$
0
6
0
1
1

An experimental oxide dispersion strengthened (ODS) alloy, WAZ-D, derived from the WAZ-20 composition was produced by the mechanical alloying process. Cast WAZ-20 is strengthened by both a high refractory metal content, and 70 volume percent of gamma prime. The ODS alloy WAZ-D, was responsive to variables of alloy content, of attritor processing, of consolidation by extrusion, and of heat treatment. The best material produced had large highly elongated grains. It exhibited tensile strengths generally superior to a comparable cast alloy. The ODS alloy exhibited high temperature stress rupture life considerably superior to any known cast superalloy; for example, the stress rupture life of WAZ-D determined in vacuum at $1150^{\circ} \mathrm{C}\left(2100^{\circ} \mathrm{F}\right)$ and $102 \mathrm{MPa}$ (15 ksi) was approximately 1000 hours. Tensile and rupture ductility were low, as was intermediate temperature rupture life. Very low creep rates were noted and some specimens failed with essentially no third stage creep. The alloy showed some potential for low stress post-extrusion forming. Comparison of WAZ-D to conventionally cast WAZ-2O and to directionally solidified WAZ-20 indicates that oxide dispersion strengthening may be beneficially added to even the strongest of superalloy compositions. Also the benefit derived from the oxide dispersion, in conjunction with the elongated microstructure, far out-weighed that from the elongated microstructure alone. 

$760^{\circ}, 1040^{\circ}, 1095^{\circ}, 1150^{\circ}$, and $1205^{\circ} \mathrm{C}$ (Table 3). All stress rupture tests were conducted in vacuum, as were tensile tests above $1205^{\circ} \mathrm{C}$. Specimens were prepared for optical and electron microscopy by standard metallographic techniques. For optical microscopy, an etchant of $2.5 \mathrm{gFeCl}_{3}, 2.5 \mathrm{gCuCl}_{2}$, $10 \mathrm{mlHNO}_{3}, 30 \mathrm{mlHCl}$, and $30 \mathrm{ml}$ ethyl alcohol was used. For electron microscopy, ion etching was used. Fracture surfaces were examined by scanning electron microscopy.

\section{RESULTS AND DISCUSSION}

\section{Microstructures}

The most uniform mechanically alloyed powder (Fig. 1) was produced using the lower oxygen flow rate and longer processing time. The most uniform highly elongated microstructures, (Fig. 2), resulted from extrusion of this powder at $1095^{\circ} \mathrm{C}$ and a 20:1 reduction ratio. Less attrition processing time and higher extrusion temperatures were less favorable to complete recrystallization while the use of 16.1 extrusion ratio produced a less elongated grain structure. Only materials which were extruded at 20:I were mechanically tested. Some of the material contained inclusions of either oxide stringers or prealloyed powder particles which escaped the mechanical alloying process unscathed; because these inclusions affected rupture lives, the tabulated rupture data (Table 3) include a microstructural rating. Oxide stringers may be avoided by protecting the powder from air exposure while at elevated temperature; unmilled particles, particularly deleterious to stress rupture life, may be avoided by control of the milling process, and may be readily detected by optical microscopy examination of the mechanically alloyed powder prior to extrusion.

The recrystallization process was quite temperature sensitive; the degree of recrystallization was 5 percent at $1290^{\circ} \mathrm{C}$, 100 percent at $1315^{\circ} \mathrm{C}, 80$ percent at $1340^{\circ} \mathrm{C}$, and $0^{\circ}$ at $1380^{\circ} \mathrm{C}$. No evidence of melting in WAZ-D was observed at $1380^{\circ} \mathrm{C}$. Recrystallized grains were always elongated for rapidly heated specimens (e.g. to temp. in 5 min.) while slow heating (from $1200^{\circ}$ to $1320^{\circ} \mathrm{C}$ in one hour) resulted in large, but more nearly equiaxed grains. Typical grain dimensions for optimally heat-treated WAZ-D were $0.6 \mathrm{~mm}$ in the longitudinal direction and $0.045 \mathrm{~mm}$ in the transverse direction, while the asextruded material had equiaxed grains of only about $0.6 \mu \mathrm{m}$ diameter. Thus, the growth of each large grain consumed on the order of ten million small grains.

The oxide dispersion observed in the recrystallized product (Fig. 3) was characterized by a mixture of fine and coarse particles. The largest were on the order of $1 \mu \mathrm{m}$, most were small, less than $0.1 \mathrm{~lm}$. The interparticle spacing determined by lineal analysis was $0.4 \mu \mathrm{m}$. Calculations based on the analysis of the products (Table 1 ) indicate a total volume fraction of 4.5 percent hard phases, primarily oxides. This is consistent with previous observation in mechanically alloyed material (ref. 3) in which the total hard phase content exceeded the intentional additions by almost 3 percent. Chemical analysis also revealed a pickup during the milling process of about 4 percent iron, considerably more than is usual in superalloys, either conventional or mechanically alloyed.

Tensile properties

The results of individual tensile tests of large elongated grain WAZ-D are listed in Table 2 and are shown graphically in Figure 4. Both contain comparable data from reference 4 for cast WAZ-20. The tensile strength of elongated grain ODS WAZ-D was not highly affected by the inclusions appearing in some powder blends.

From Table 2 and Figure 4 it may be noted that the tensile strength of WAZ-D was generally above that of cast WAZ-20, coinciding only at $1095^{\circ} \mathrm{C}$. The improvement at low temperature is typical of a powder metallurgy product 
and is thought to be caused more by a finer distribution of gamma prime than by the added hard phase dispersion. The improvement at higher temperatures is more significant, especially since WAZ-20 is one of the strongest nickel based alloys at $1200^{\circ} \mathrm{C}$. Also significant is the $83 \mathrm{MPa}$ ( $12 \mathrm{ksi}$ ) tensile strength of WAZ-D at $1315^{\circ} \mathrm{C},\left(2400^{\circ} \mathrm{F}\right)$ at or above the incipient melting temperature of cast WAZ-20. The tensile ductility values (Table 2) for WAZ-D are generally below those of directionally solidified WAZ-20 and similar to those of conventionally cast WAZ-20. It is interesting to note, that the room temperature (R.T.) reduction in area and elongation were both increased by prior thermal exposure under creep conditions. This suggests that the properties of WAZ-D may be affected by post recrystallization heat treatment, a possibility not fully investigated here.

Workability

Another interesting feature not represented in the listed tensile data was that the as-extruded material, though brittle at R.T., had the high plasticity (e.g. greater than 100 percent elongation) at elevated temperature associated with very fine grains. It could be strained in tension under low stress (e.g., $27 \mathrm{MPa}, 4 \mathrm{ksi}$ ) at $1040^{\circ}$ or $1095^{\circ} \mathrm{C}$ and then converted by $1320^{\circ} \mathrm{C}$ annealing to a large elongated grain material. This indicates that WAZ-D and perhaps other ODS alloys may be worked at high temperatures and low stresses prior to recrystallization to a creep resistant microstructure. The working would best be carried out in compression to avoid the porosity and cracks which occur during tensile straining of the unrecrystallized material.

\section{Stress rupture properties}

From the stress rupture data (Table 3 and Fig. 5) it may be observed that the large elongated grain dispersion strengthened alloy WAZ-D provides a considerable stress rupture life advantage over the comparable cast alloy. And since comparison was made to the cast alloy of even larger and more elongated grains prepared by directional solidification, most of the advantage may be ascribed to the hard phase dispersion. A comparison at $103 \mathrm{MPa}$ (15 ksi) and $1150^{\circ} \mathrm{C}\left(2100^{\circ} \mathrm{F}\right)$ indicates a rupture life improvement of two orders of magnitude from 5 hours for the cast material to approximately 1000 hours for WAZ-D. Alternatively, this may be considered as in Figure 6 as a use temperature advantage of $130^{\circ} \mathrm{C}$ over the strongest conventional cast a.loys (ref. 6) or $90^{\circ} \mathrm{C}$ over the gamma-gamma prime-delta directionally solidified eutectic, (ref. 7) itself a candidate material for advanced gas turbine blades.

It may also be observed that the stress rupture life was strongly affected by the microstructure, unprocessed particles being particularly deleterious. Fracture of WAZ-D was primarily transgranular, even for long life rupture specimens. The voids which formed at transverse grain boundaries during high temperature testing, either tensile or rupture, appeared to be too few, and too scattered to provide a continuous fracture path. Fracture surfaces were generally quite rough. Longitudinal cracks were evident along grain boundaries in specimens fractured at high temperature (Fig. 7), and in specimens tested at R.T. after high temperature creep exposure. From the formation of these cracks, it is surmized that transverse properties, not measured in this investigation, would be low.

Stress rupture curves, recorded by monitoring a dial gauge affixed to the load train, showed total strains generally in the range of 1.5 percent. About 1 percent occurred soon after loading, for example, within the first 5 percent of sample life. Strain rate continued to decrease through most of the sample life. The curves turned upward only brief'ly before fracture. The decrease in strain rate with increasing time was in contrast to the increasing rate shown for MA-753 (ref. 8), and may be related to the formation during creep exposure of very large (600 um wide, $100 \mu$ thick) gamma prime platelets (Fig. 7). As in reference 9 these gamma prime plates grew transverse to the applied tensile 
.

. 
stress. The growth of some appeared to have increased the grain boundary roughness, and thus may be hindered grain boundary sliding. Approximate strain rates, covering the latter 80 percent of sample life and listed in Table 3, increased by an order of magnitude as the temperature increased from $1095^{\circ} \mathrm{C}$ $\left(2000^{\circ} \mathrm{F}\right)$ to $1205^{\circ} \mathrm{C}\left(2200^{\circ} \mathrm{F}\right)$ and by two orders of magnitude as stress at $1095^{\circ} \mathrm{C}$ increased from $103 \mathrm{MPa}$ (15 ksi) to $172 \mathrm{MPa}(25 \mathrm{ksi})$. The strain during this period (the latter 80 percent of life and prior to any third stage) ranged from 0.16 percent to 0.51 percent but for most specimens was approximately 0.25 percent.

\section{Effect of alloy content}

Decreasing the tungsten in WAZ - D from 17 to 8 percent decreased the $1095^{\circ} \mathrm{C}$ $\left(2000^{\circ} \mathrm{F}\right.$ ) tensile strength from $303 \mathrm{MPa}(44 \mathrm{ksi})$ to $207 \mathrm{MPa}$ (30 ksi). The R.T. tensile strength was decreased from $1570 \mathrm{MPa}$ (227 ksi) to $1240 \mathrm{MPa}$ (180 ksi) with both 10 percent elongation and reduction in area. After 700 hour $1095^{\circ} \mathrm{C}$ $\left(2000^{\circ} \mathrm{F}\right) 103 \mathrm{MPa}$ ( $15 \mathrm{ksi}$ ) exposure, the R.T. tensile strength was $104 \mathrm{MPa}$ (151 ksi) and reduction in area was 19 percent. The stress rupture life at $1095^{\circ} \mathrm{C}\left(2000^{\circ} \mathrm{F}\right)$ was at least an oxder of magnitude improved over cast WAZ-20 placing the 8 percent W ODS alloy above all conventional cast alloys, but below the 17 percent W WAZ-D. Rupture ductility was 1 percent or less. Thus, decreasing the tungsten content decreased both tensile and stress rupture strengths and increased tensile but not rupture ductility.

\section{CONCLUDING REMARKS}

It was shown that a high $r^{\prime}$ fraction alloy having a high gamma prime solvus temperature can be effectively dispersion strengthened. The strengths obtained were outstanding, especially at $1150^{\circ}$ and $1205^{\circ} \mathrm{C}$.

The strength was derived from the highly alloyed matrix, the elongated grain structure, and the hard phase dispersion all working in conjunction. The demonstrated tensile and rupture ductilities were low; however, it was shown that the tensile ductility can be improved by post-recrystallization heat treatment. It was also shown that the material could be strained at low stress at elevated temperature in the fine grained state, and then converted to a creep resistant microstructure. If this feature is applicable to other ODS alloys, it may provide a valuable tool for forming the complex shapes required for gas turbine hardware.

\section{REFERENCES}

1. Benjamin, J. S., "Dispersion Strengthened Superalloys by Mechanical Alloying,"" Metallurgical Transactions, Vol. 1, Oct. 1970, pp. 2943-2951.

2. Cairns, R. I., Curwick, I. R., and Benjamin, J. S., "Grain Growth in Dispersion Strengthened Superalloys by Moving Zone Heat Treatments," Metallurgical Transactions, Vol. 6A, Jan. 1975, pp. 179-188.

3. Glasgow, T. K., Quatinetz, M., "Preliminary Study of Oxide-DispersionStrengthened B-1.900 Prepared by Mechanical Alloying," NASA TM X-3303, oct. 1975.

4. Waters, J. W. and Freche, J. C., "A Nickel Base Alloy, WAZ-20, with Improved Strength in the $2000^{\circ}$ to $2200^{\circ}$ F Range, "NASA TN D-5352, Aug. 1969.

5. Benjamin, J. S., "Dispersion-Strengthened Superalloys," U.S. Patent 3,776, 704, Dec. 1973.

6. High Temperature High Strength Nickel Base Alloys. The International Nickel Company, Inc., 1964. 
.

. 
7. Gray, H. R., Sanders, W. A., "Effect of Thermal Cycling in a Mach 0.3 Burner Rig on Properties and Structure of Directionally Solidified $\gamma / \gamma^{\prime}-\delta$ Eutectic," NASA TM X-3271, Oct. 1975; and Proc. of Conf. on IN-SITU Composites-II, 1975.

8. Strobel, C. R., "A Nickel-Base Alloy with Unusual Creep Behavior," Metals Engineering Quarterly, Vol. 14, May 1974, pp. 12-16.

9. Tien, J. K., and Copley, S. M., "The Effect of Uniaxial Stress on the Periodic Morphology of Coherent Gamma Prime Precipitates in Nickel-Base Superalloy Crystals," Metallurgical Transactions, Vol. 2, Jan. 1971, pp. 215-219. 
TABLE 1. - COMPOSITION ${ }^{1}$ (\%) AND DENSITY (g/ce) OF ALUOYS

\begin{tabular}{|c|c|c|c|c|c|c|c|c|c|c|c|}
\hline A.lloy & $\mathrm{Ni}$ & W & $\mathrm{A} I$ & $\mathrm{Fe}$ & $\mathrm{Zr}$ & B & C & 0 & N & $\mathrm{Y}$ & o \\
\hline$(16)$ & B & 1 & 7. & 4.3 & $0.6^{2}$ & N.I & 0. & 0.5 & 0. & & \\
\hline (8W) & BA & 7. & 6. & 4.5 & $0.5^{2}$ & N. & & $0.51^{4}$ & C & 0.8 & \\
\hline & BAL & 18 & 6.0 & -- & 1.5 & 0.0003 & 0.11 & --- & -- & -- & \\
\hline
\end{tabular}

1. Analyses performed in house on extruded and heat treated bar.

2. Analysis believed in error; added $\mathrm{Zr}$ was $0.95 \%$.

3. Not determined, 0.015 added.

4. For $3.5 \mathrm{ml} / \mathrm{min} \mathrm{O}_{2}, 40$ hour runs.

5. Reference 4.

TABLE 2. - RESUTTS OF TENSTLE TESTS OF LARGE ELONGATED GRAIN ODS WAZ-D (17W) AND COMPARABLE DATA FOR CAST WAZ-20

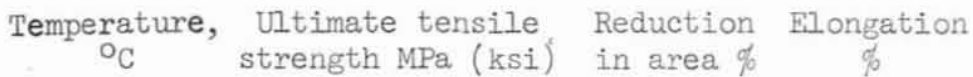

\begin{tabular}{cclll}
\multicolumn{7}{c}{ ODS-WAZ-D } & $(17 \mathrm{~W})$ & & \\
Room temp. & 1572 & $(228)$ & 3 & 7 \\
$"$ & 1565 & $(227)$ & 3 & 5 \\
$"$ & 1358 & $(197) 1$ & 7.7 & 7.3 \\
$"$ & 1331 & $(193)^{2}$ & 9 & 17 \\
$760^{\circ}$ & 903 & $(131)$ & 2 & 1 \\
$760^{\circ}$ & 917 & $(133)$ & 5 & 4 \\
$1095^{\circ}$ & 290 & $(42)$ & 2 & 2 \\
$1095^{\circ}$ & 303 & $(44)$ & 0 & 5 \\
$1205^{\circ}$ & 221 & $(32)$ & 2 & 3 \\
$1205^{\circ}$ & 186 & $(27)$ & 0 & 3 \\
$1260^{\circ}$ & 124 & $(18)$ & 0 & 1 \\
$1315^{\circ}$ & 80 & $(12)$ & 0 & 1
\end{tabular}

WAZ-20, conventionally cast (ref. 4)

$\begin{array}{ccccc}\text { Room temp. } & 745 & (108) & \text { N.R. } 3 & 4 \\ 760^{\circ} & 752 & (109) & \text { N.R. } 3 & 4 \\ 1095^{\circ} & 303 & (44) & \text { N.R. } 3 & 4 \\ 1205^{\circ} & 138 & (20) & \text { N.R. } 3 & 5\end{array}$

WAZ-20, directionally solidified (ref. 4)

$\begin{array}{crrrr}\text { Room temp. } & 896 & (130) & \text { N.R. } & 13 \\ 760^{\circ} & 827 & (120) & \text { N.R. } & 4 \\ 1095^{\circ} & 303 & (44) & \text { N.R. } & 12 \\ 1205^{\circ} & 138 & (20) & \text { N.R. } & 8\end{array}$

1. Determined after 360 hour (20 ksi), $1095^{\circ} \mathrm{C}$ creep exposure.

2. Determined after 1220 hour ( $15 \mathrm{ksi}), 1150^{\circ} \mathrm{C}$ creep exposure.

3 . Not reported. 
. 
TABLE 3. - RESULTS OF VACUUM STRESS-RUPIURE TESTS OF ODS WAZ-D (17W) AND COMPARABLE DATA FOR CAST WAZ-20 TESTED IN AIR

\begin{tabular}{|c|c|c|c|c|c|c|}
\hline$\underset{{ }^{\circ} \mathrm{C}}{\text { Temp. }}$ & Microstructure ${ }^{1}$ & $\begin{array}{l}\text { Stress } \\
\text { MPa (ksi) }\end{array}$ & $\begin{array}{l}\text { Rupture } \\
\text { life, hrs }\end{array}$ & $\underset{\%}{\text { R.A. }}$ & $\underset{\%}{\text { Elong. }}$ & $\begin{array}{l}\text { Strain } \\
\text { rate, } \mathrm{sec}^{-1}\end{array}$ \\
\hline \multicolumn{7}{|c|}{ ODS-WAZ-D ( $17 W)$, vacuum test } \\
\hline 760 & B & $572(83)$ & 9 & 0 & 1 & N.D. \\
\hline 760 & C & 572 (83) & 3 & 0 & 1 & N.D. \\
\hline 1040 & D & 103 (15) & 0 & 77 & 126 & N. D. \\
\hline 1040 & C & 103 (15) & 147 & 0 & & N.D. \\
\hline 1095 & A & 103 (15) & $1125 t^{2}$ & N.A. ${ }^{3}$ & N.A. & $8.6 \cdot 10^{-}$ \\
\hline 1095 & B & 103 (15) & 995 & I & 1 & $5.6 \cdot 10^{-}$ \\
\hline 1095 & C & $103(15)$ & 68 & 0 & 1 & N.D. \\
\hline 1095 & A & 138 (20) & $357 t^{2}$ & N.A. & N.A. & $2.7 \cdot 10^{-5}$ \\
\hline 1095 & B & $138(20)$ & 73 & 0 & 1 & $1.4 \cdot 10^{-8}$ \\
\hline 1095 & A & 172 (25) & 41 & 1 & 1 & $3.1 \cdot 10^{-8}$ \\
\hline 1095 & B & 172 (25) & 3 & I & 1 & N.D. \\
\hline 1150 & A & 103 (15) & $95 t^{4}$ & 0 & 2 & N.D. \\
\hline 1150 & A & 103 (15) & 674 & 7.8 & 0 & $1.4 \cdot 10^{-}$ \\
\hline 1150 & A & 103 (15) & 706 & 0 & 0 & $1.5 \cdot 10^{-9}$ \\
\hline 1150 & B & 103 (15) & $1273 t^{2}$ & N.A. & N.A. & $1.3 \cdot 10^{-9}$ \\
\hline 120 & A & 103 (15) & 95 & 5 & 1.4 & $2.0 \cdot 10^{-8}$ \\
\hline 1205 & A & 103 (15) & 112 & 6.4 & 3 & $8.5 \cdot 10^{-}$ \\
\hline
\end{tabular}

Conventionally cast WAZ-20, air test (ref. 4)

1040

1095

1150

$\begin{array}{lrrlll}E & 103(15) & 100 & N^{5} & N R & N R \\ E & 103(15) & 20 & N R & N R & \text { NR } \\ E & 103(15) & 5 & \text { NR } & \text { NR } & \text { NR }\end{array}$

Directionally solidified WAZ-20, air test (ref. 4)

$\begin{array}{rrrrrrr}760 & \text { F } & 572(83) & 75^{6} & 3 & 4 & \text { NR } \\ 1040 & \text { F } & 103(15) & 190 & \text { NR } & \text { NR } & \text { NR } \\ 1095 & \text { F } & 103(15) & 42 & \text { NR } & \text { NR } & \text { NR } \\ 1150 & \text { F } & 103(15) & 4 & \text { NR } & \text { NR } & \text { NR }\end{array}$

1. Microstructures:

A. Recrystallized, large elongated, very few inclusions.

B. Recrystallized, large elongated, some few inclusions, mainly stringers.

C. Recrystallized, large elongated, many inclusions, mainly unprocessed particles.

D. As extruded, fine grained, equiaxed.

E. Conventionaliy cast, large equiaxed grains.

F. Directionally solidified, large elongated grains.

2. Discontinued test

3. Not applicable

4. After 1031 hours at $103 \mathrm{MPa}, 1095^{\circ} \mathrm{C}$

5. Not reported

6. Single test, this work 


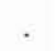



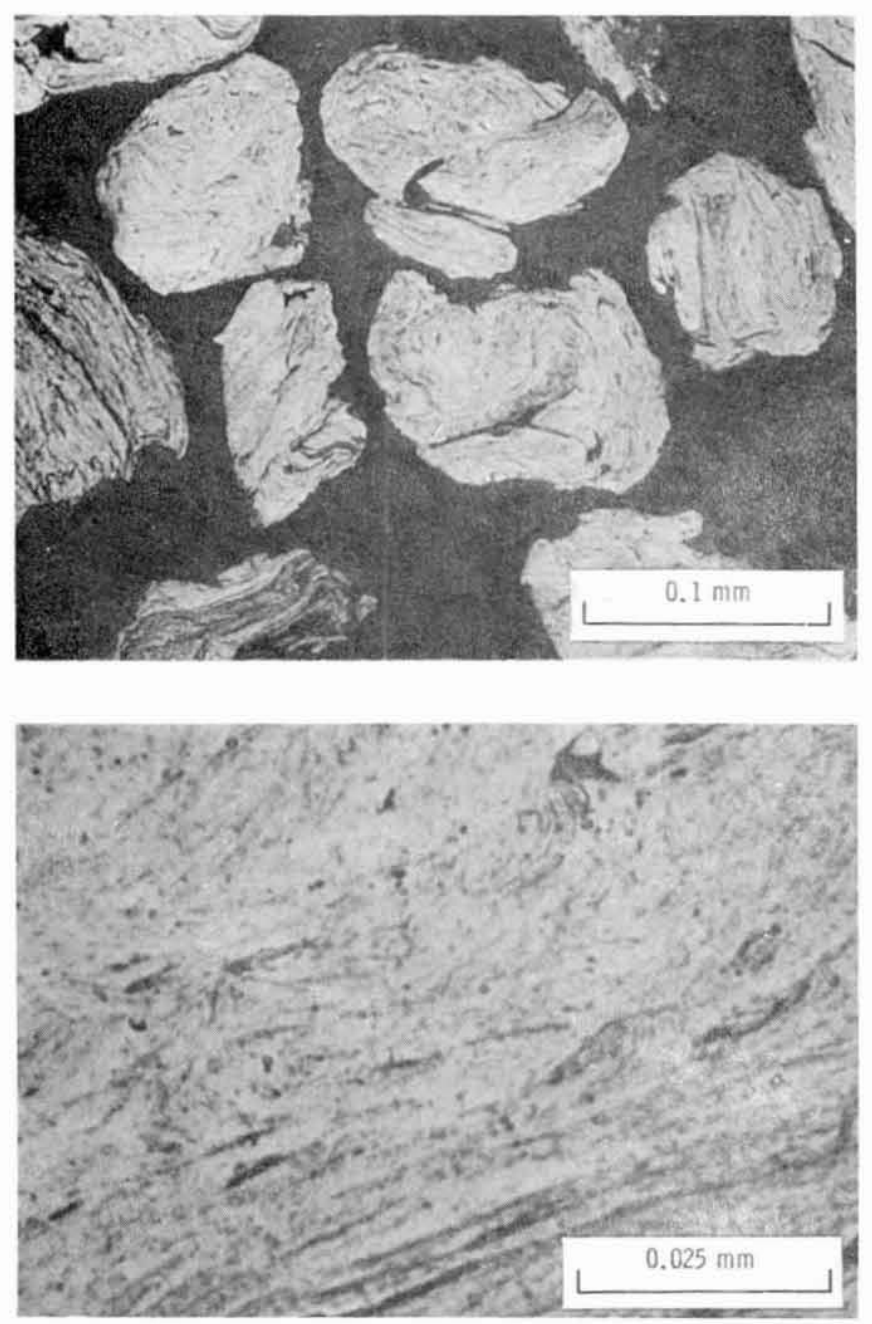

Figure 1. - Structure of mechanically alloyed WAZ-D powder.

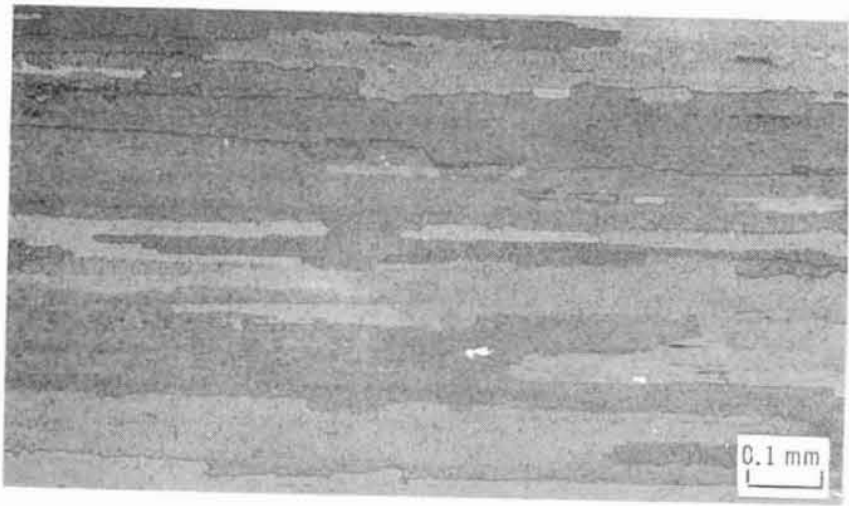

Figure 2. - Gradient annealed WAZ-D (17 W). 


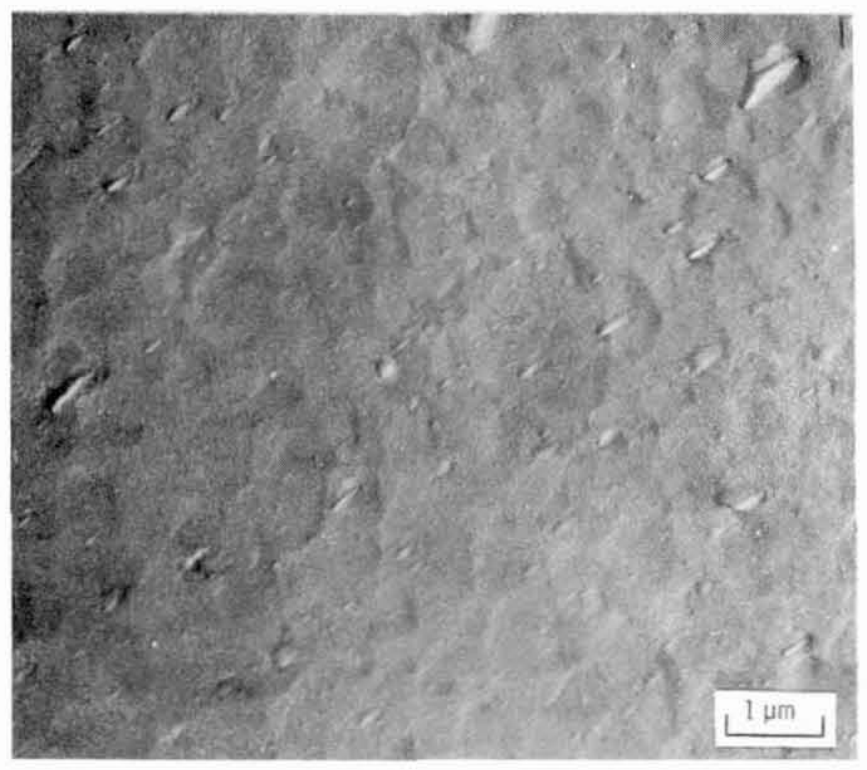

Figure 3. - Fine and coarse hard phase particles in WAZ-D after $1315^{\circ} \mathrm{C}$ $(2400 \mathrm{f})$ anneal. As ion etched.

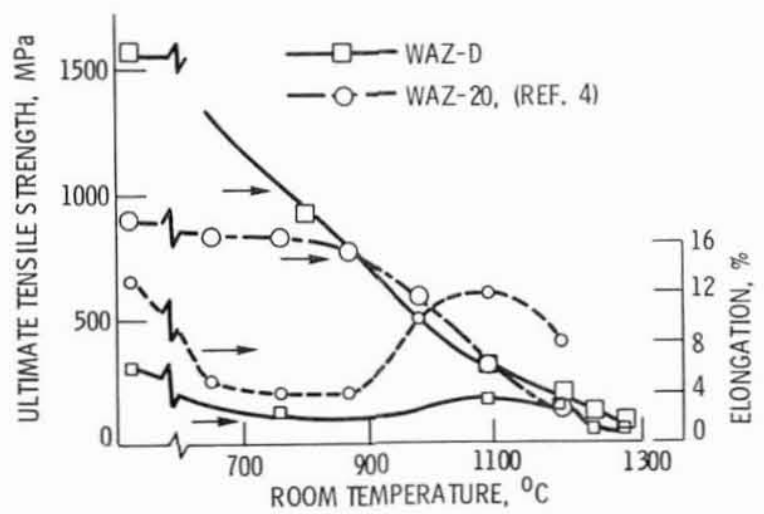

Figure 4. - Ultimate tensile strength and elongation of ODS WAZ-D and directionally solidified WAZ-20. 


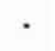




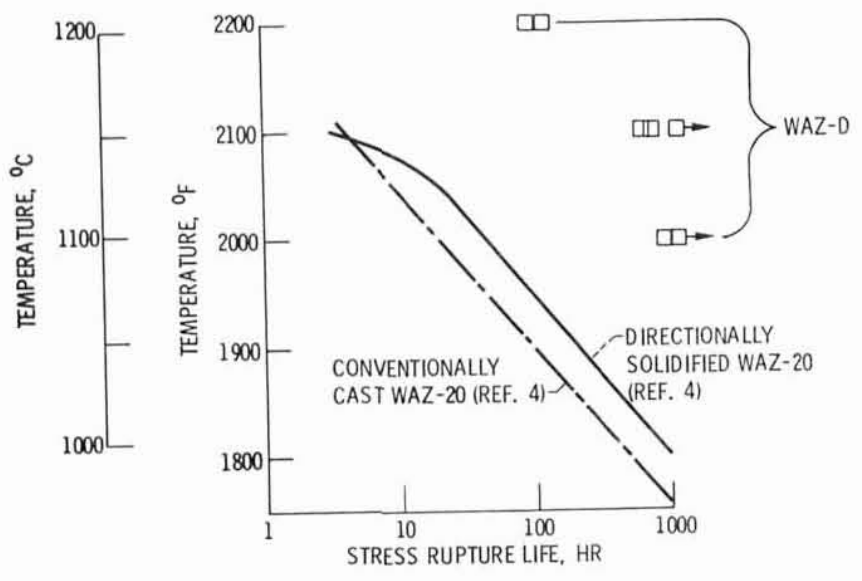

Figure 5. - Stress rupture lives of WAZ-D and WAZ-20.

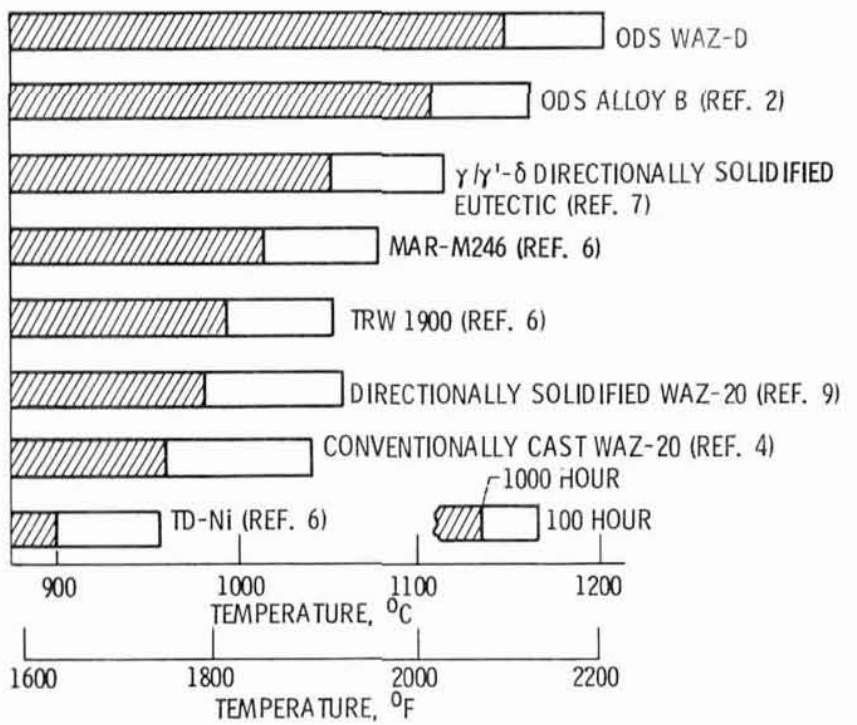

Figure 6. - Temperature to produce rupture at $103 \mathrm{MPa}(15 \mathrm{ksi})$ in 100 and 1000 hours for advanced and conventional alloys. 


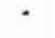




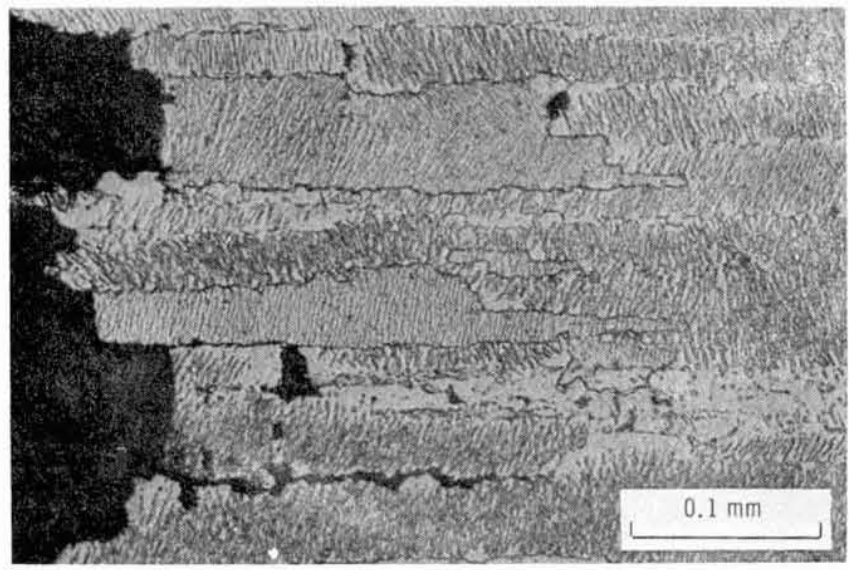

Figure 7. - WAZ-D showing development of gamma prime plates and transgranular fracture after 100 hour, $1205^{\circ} \mathrm{C}, 103 \mathrm{MPa}(15 \mathrm{ksi})$ rupture life. 


\section{'}

